\title{
Simplified Seismic Loss Estimation of RC Frame using Component-performance-based Methodology
}

\author{
Shengfang Qiao ${ }^{1,2,3}$, Mengxiong Tang ${ }^{1,2}$, Xiaolei $\mathrm{Han}^{3}$, Hang $\mathrm{Chen}^{1}$, Han $\mathrm{Hu}^{1,3}$, Hesong $\mathrm{Hu}^{1}$, Cunlin $\mathrm{Liu}^{1,3}$, and \\ Zhenkun Hou ${ }^{1,3}$ \\ ${ }^{1}$ Guangzhou Institute of Building Science Co., Ltd., Guangzhou, China \\ ${ }^{2}$ Guangzhou Construction Engineering Co., Ltd., Guangzhou, China \\ ${ }^{3}$ South China University of Technology, Guangzhou, China
}

\begin{abstract}
A framework of simplified probabilistic seismic loss estimation of RC frame using componentperformance -based methodology was presented in this paper. Firstly, component- performance -based methodology was introduced, and component performance level was measured using elasto-plastic rotation angle of structural component. Then structural performance level was determined by the statistics of damaged components distribution. Additionally, the relationship between the structural performance level and loss ratio of RC frame was established. Last, expected seismic loss ratio of 3-storey RC frame was studied in detail. This study reveals that the simplified probabilistic framework proposed herein could be used in RC frame.
\end{abstract}

\section{Introduction}

Generally, code-conforming RC frame has the certain ductile to meet the goal, which has been confirmed in past earthquakes [1]. However, enormous economic loss was induced due to the deficiency in traditional design philosophy. Considering the unacceptable economic loss in past earthquakes, the next-generation probabilistic PBSD [2] was come upon, which was the PEER framework. The seismic loss in low-rise building was discussed based on PEER framework [3]. FEMA P58 [4] was issued by summarizing many years effort of the next-generation PBSD. The seismic losses of ductile and non-ductile RC frames were studied using PEER framework [5]. The simplified PEER framework was also presented using macro deformation indicators, e.g. interstorey drift ratio [6].

The probabilistic PBSD method has been widely used to seismic assessment within the academia, however, it was far unfamiliar to practicing engineers. Therefore, simplified probabilistic PBSD method was significant to be proposed, which could help practicing engineers to comprehend and implement probabilistic PBSD. Furthermore, the inter-storey drift ratio was not coincident with the damaged structural components strictly [7]. In this paper, simplified seismic loss estimation framework using component- performance based methodology (or SSLEFCPM) was presented, which aim was to facilitate the familiarity and application of probabilistic PBSD method. Business interruption and casualty beyond the range of this study were not considered herein.

\section{Presentation of SSLEFCPM}

The SSLEFCPM could be divided into four stages, including seismic risk analysis, structural nonlinear analysis, structural performance level(SPL) analysis and loss analysis.

\subsection{Seismic risk analysis}

In order to portray the seismic risk analysis using a probabilistic form, the seismic risk model was used herein.

$$
\lambda(\mathrm{im})=k_{0}(\mathrm{im})^{-k}
$$

$k$ and $k_{0}$ were constant. im was intensity measure and represented using peak ground acceleration(or $P G A$ ), and $\lambda(\mathrm{im})$ was annual probability of earthquake.

\subsection{Structural analysis}

The goal of structural analysis was to obtain structural response parameters under different intensity measures. FEMA P58 [4] proposed at least 7 pairs of earthquake records.

\subsection{Damage analysis}

\subsubsection{Component performance level and acceptance criteria}


The acceptance criterion of elasto-plastic rotation angle for component performance level (CPL) was introduced at length[8]. However, the acceptance criteria were too conservative to use in most buildings, even in old existing buildings [9]. Hence, the acceptable criteria was extended on the basis of plentiful experimental data [7]. Furthermore, six performance $\operatorname{limits}\left(P_{1} \sim P_{6}\right)$ and seven performance levels $\left(L_{1} \sim L_{7}\right)$ were presented in terms of the damage extent of components themselves.

\subsubsection{Structural performance level and acceptance criteria}

Seven structural performance levels (SPLs, S-1 S-7) were presented [7], and SPLs can be determined according to the damage distribution of structural components in Table 1. Local collapse or total collapse may be triggered in case of vertical bearing capacity loss in column, and the structure will be tough to be repaired due to the column failure [8]. Hence, the column failure was taken as the collapse prevention(S-7) herein, which was consistent with the vertical bearing capacity loss of column. Moreover, the structure will collapse once dynamic instability occurs, therefore, the dynamic instability was also considered.

Table 1. Damaged components distribution for the acceptance criteria of SPLs

\begin{tabular}{|c|c|c|c|c|c|c|c|}
\hline $\begin{array}{l}\text { CPLs } \\
\text { SPLs }\end{array}$ & $L_{1}$ & $L_{2}$ & $\boldsymbol{L}_{3}$ & $L_{4}$ & $L_{5}$ & $L_{6}$ & $L_{7}$ \\
\hline $\begin{array}{c}\text { Insignific } \\
\text { ant } \\
\text { damage(S } \\
-1)\end{array}$ & -- & $5 \%$ & $0 \%$ & $0 \%$ & $0 \%$ & $0 \%$ & $0 \%$ \\
\hline $\begin{array}{c}\text { Minor } \\
\text { damage(S } \\
-2)\end{array}$ & -- & $\begin{array}{l}30 \\
\%\end{array}$ & $5 \%$ & $0 \%$ & $0 \%$ & $0 \%$ & $0 \%$ \\
\hline $\begin{array}{c}\text { Limited } \\
\text { moderate } \\
\text { damage(S } \\
-3)\end{array}$ & -- & $\begin{array}{l}50 \\
\%\end{array}$ & $\begin{array}{l}30 \\
\%\end{array}$ & $5 \%$ & $0 \%$ & $0 \%$ & $0 \%$ \\
\hline $\begin{array}{c}\text { Moderate } \\
\text { damage(S } \\
-4)\end{array}$ & -- & -- & $\begin{array}{l}50 \\
\%\end{array}$ & $\begin{array}{l}30 \\
\%\end{array}$ & $5 \%$ & $0 \%$ & $0 \%$ \\
\hline $\begin{array}{c}\text { Limited } \\
\text { serious } \\
\text { damage(S } \\
-5)\end{array}$ & -- & -- & -- & $\begin{array}{l}50 \\
\%\end{array}$ & $\begin{array}{l}30 \\
\%\end{array}$ & $5 \%$ & $0 \%$ \\
\hline $\begin{array}{c}\text { Serious } \\
\text { damage(S } \\
-6)\end{array}$ & -- & -- & -- & -- & $\begin{array}{l}50 \\
\%\end{array}$ & $\begin{array}{l}30 \\
\%\end{array}$ & $5 \%$ \\
\hline $\begin{array}{c}\text { Collapse } \\
\text { preventio } \\
\text { n(S-7) }\end{array}$ & & & & it $\mathrm{f}$ & & tan & \\
\hline
\end{tabular}

A given SPL in Table 1 means the percentage of damaged component exceeds the limit of the former row. The SPL of the structure was taken as S-7 if the distribution of component performance level (CPL) could not satisfy any SPL listed. The “--” means that the percentage of damaged components was unconfined.

\subsubsection{Structural performance level to loss model}

Aforementioned SPLs can be determined according to the distribution of damaged structural components. Moreover, the relevant loss ratios of SPLs of RC frame were demonstrated in Table 2 based on GBT 18208.4 [10], which were the repair cost of SPLs. In the same way, the SPL to loss model could also be established according to standards or guidelines in other countries.

Table 2. Loss ratios of RC frame

\begin{tabular}{|c|c|c|c|}
\hline SPLs & Description & $\begin{array}{c}\text { Loss ratio } \\
(\%)\end{array}$ & $\begin{array}{c}\text { Median } \\
(\%)\end{array}$ \\
\hline $\mathrm{C}_{0}$ & Undamaged & 0 & 0 \\
\hline $\mathrm{C}_{1}$ & $\begin{array}{c}\text { Repair cost of } \\
\text { insignificant damage }\end{array}$ & $0 \sim 5$ & 3 \\
\hline $\mathrm{C}_{2}$ & $\begin{array}{c}\text { Repair cost of minor } \\
\text { damage }\end{array}$ & $6 \sim 15$ & 11 \\
\hline $\mathrm{C}_{3}$ & $\begin{array}{c}\text { Repair cost of limited } \\
\text { moderate damage }\end{array}$ & $11 \sim 31$ & 21 \\
\hline $\mathrm{C}_{4}$ & $\begin{array}{c}\text { Repair cost of } \\
\text { moderate damage }\end{array}$ & $16 \sim 45$ & 31 \\
\hline $\mathrm{C}_{5}$ & $\begin{array}{c}\text { Repair cost of limited } \\
\text { serious damage }\end{array}$ & $31 \sim 73$ & 52 \\
\hline $\mathrm{C}_{6}$ & $\begin{array}{c}\text { Repair cost of serious } \\
\text { damage }\end{array}$ & $46 \sim 100$ & 73 \\
\hline $\mathrm{C}_{7}$ & $\begin{array}{c}\text { Repair cost of } \\
\text { collapse prevention }\end{array}$ & $81 \sim 100$ & 91 \\
\hline
\end{tabular}

\subsection{Loss analysis}

The expected seismic loss E(loss|im) was presented when $I M=i m$.

$$
E(\operatorname{loss} \mid i m)=\sum_{i=1}^{n S P L} P\left(\mathrm{~S}_{i} \mid i m\right) \cdot E\left(\mathrm{C}_{i} \mid \mathrm{S}_{i}\right)
$$

$P\left(\mathrm{~S}_{i} \mid\right.$ im $)$ and $E\left(\mathrm{C}_{i} \mid \mathrm{S}_{i}\right)$ were the probability and expected repair cost of structural performance level $i$. The median of loss ratio in Table 2 was used for $E\left(\mathrm{C}_{i} \mid \mathrm{S}_{i}\right)$. nSPL was the number of structural performance level.

\section{Numerical example}

\subsection{Architecture archetype}

3-storey RC frames(or 3S) were designed according to GB50011 [11], and the plan layout was same and described in Fig. 1(a). The annual exceedance frequency(or $\lambda$ ) and PGA under minor, moderate, rare and very rare earthquake were demonstrated in Table 3 . The storey height of $1 \mathrm{st}$ floor was $4.5 \mathrm{~m}$, and other floors were $3.6 \mathrm{~m}$. The distributed dead and live loads were $3.5 \mathrm{kN} / \mathrm{m} 2$ and $2.0 \mathrm{kN} / \mathrm{m} 2$ on the floors. Distributed linear load acted on beams was $8.0 \mathrm{kN} / \mathrm{m}$. Steel yielding stress 
of $\mathrm{C}$ was $335 \mathrm{MPa}$ and $\mathrm{D}$ was $400 \mathrm{MPa}$. The performance limits of beams and columns could be derived [7].

Table 3. Seismic risk analysis

\begin{tabular}{|c|c|c|c|c|}
\hline Magnitude & Minor & Moderate & Rare & Very rare \\
\hline $\boldsymbol{P G} \boldsymbol{A}(\mathrm{g})$ & 0.070 & 0.200 & 0.400 & 0.714 \\
\hline$\lambda$ & $2.0 \times 10^{-2}$ & $2.1 \times 10^{-3}$ & $4.0 \times 10^{-4}$ & $1.0 \times 10^{-4}$ \\
\hline Period(years) & 50 & 475 & 2475 & 10000 \\
\hline
\end{tabular}

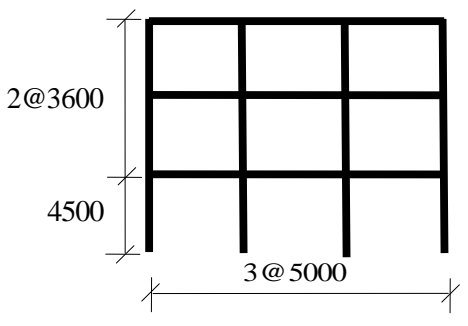

4D16+4D12;C10@100

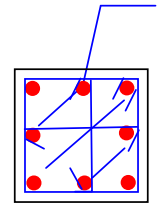

$400 \times 400$

Column of $1-3$ storey

Concrete01 for RC columns

Unconfined: $-23.4-0.002-0.1-0.0040$

Confined: $-26.3-0.0032-7.89-0.0350$

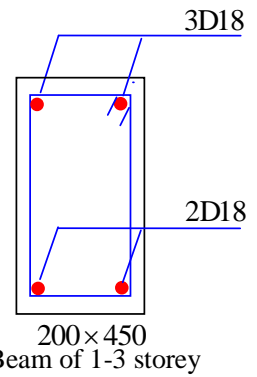

Beam of 1-3 storey

Concrete01: $-20.1-0.002-0.1-0.0040$

Fig. 1. 3-storey RC frame modeling

\subsection{Structural analysis}

\subsubsection{Model in openSEES.}

The RC frame mentioned above in Fig.1 was simulated using OpenSEES. Concrete01and Steel01 denoted the constitutive of concrete and steel. The fiber model with five integration points was used to simulate beam and column elements, and P- $\Delta$ effect was taken into account for columns. The deformation of beam-column joint was insignificant in code-conforming RC frame [3], so the rigid joint was used herein.

\subsubsection{Nonlinear time history analysis}

The 22 earthquake records [12] were used, and Rayleigh damping was $5 \%$. The damaged components distribution could be obtained once nonlinear time history analysis was finished under different $P G A$ in Table 4. And the corresponding SPL could be determined according to damaged components distribution in Table 1. For instance, damaged component distributions of 3-storey $\mathrm{RC}$ frame under earthquake record E10 in Fig. 2(a) were demonstrated in Fig. 2(b). The percentage of damaged components of $3 \mathrm{~S}$ in $L_{2}$ was $28.6 \%(6 / 21)$ and other CPLs are void when PGA was $0.25 \mathrm{~g}$, which exceeds $5 \%$ but less than $30 \%$ in Table 2. So the SPL was S-2.

In addition, the scatter diagram of cumulative probability each SPL for 3S was obtained in Fig. 3(a), and the logarithmic curve fitting were also established. As shown in Fig. 3(a), several different SPLs may be simultaneous and mutually exclusive due to different earthquake records under the same PGA, and the corresponding probabilities were calculated by the difference between two adjacent cumulative probabilistic curves. Furthermore, the related bar graph of probabilities of different SPL under different $P G A$ could be shown in Fig. 3(b).

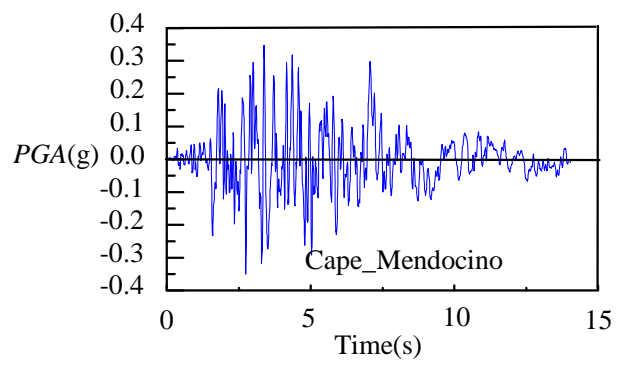

(a) Earthquake record

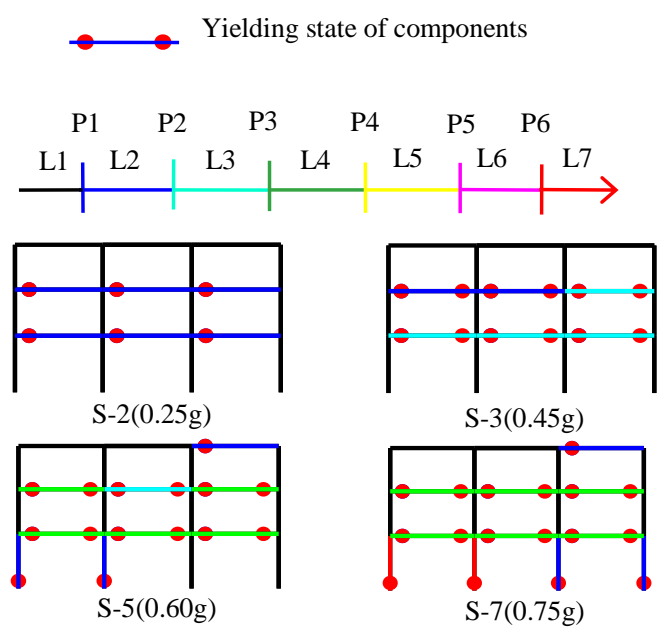

(b) SPLs of $3 \mathrm{~S}$

Fig. 2. Distributions of damaged component under different SPL

\subsubsection{Loss analysis}

The expected seismic loss ratios (ESLRs) under moderate, rare and very rare earthquake were calculated on the basis of Fig. 3(b) in Table 4. 
Table 4. ESLRs under moderate, rare and very rare earthquakes

\begin{tabular}{|c|c|c|}
\hline Moderate (\%) & Rare (\%) & Very rare (\%) \\
\hline 35.9 & 71.0 & 90.4 \\
\hline
\end{tabular}

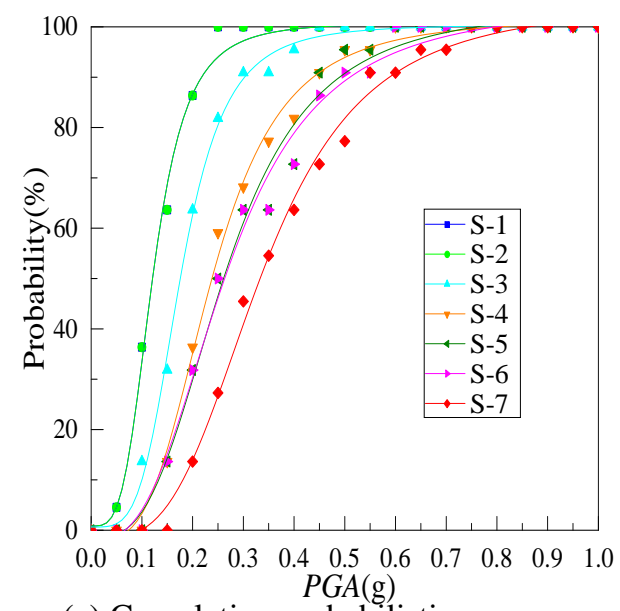

(a) Cumulative probabilistic curves

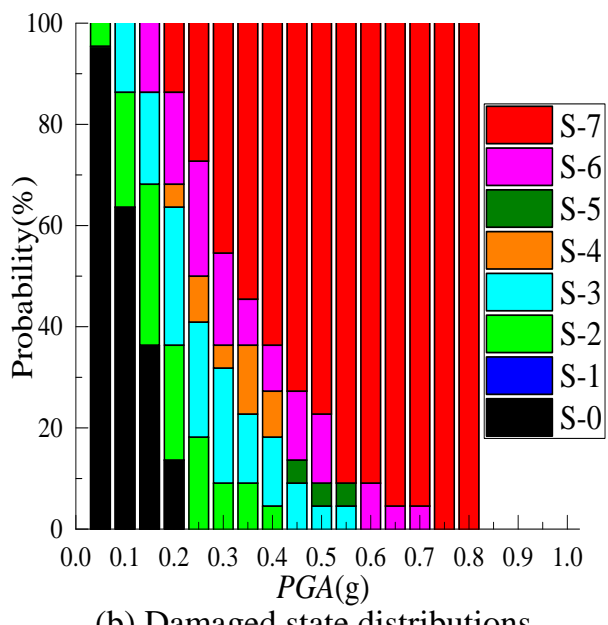

(b) Damaged state distributions

Fig. 3. Cumulative probabilistic curves and damaged state distributions

\section{Results and discussion}

In Fig. 2(b), the SPLs of 3-storey frame were S-2, S-3, S-5 and S-7 when the corresponding $P G A$ s were $0.25 \mathrm{~g}$, $0.40 \mathrm{~g}, 0.50 \mathrm{~g}$ and $0.55 \mathrm{~g}$. And the RC beams yield first, then the columns yield. It could be implied that the SPL worsens with the $P G A$ strengthens, and the actual structural damage state could be portrayed using component performance -based methodology.

In Figs. 3(b), the percentages of S-7 of 3-storey frame were $13.6 \%$ under moderate earthquake, and $63.6 \%$ under rare earthquake. The column failure(S-7) was taken as structure failure. It denotes that the percentage of structure failure due to column failure may be very remarkable under rare earthquake.

In Table 4, the expected seismic loss ratios of 3storey frame under moderate earthquake approximated $40 \%$ which was the structural demolition threshold in FEMA P58 [4] It could indicate that the structure may be demolished due to huge economic loss when the $P G A$ exceeds the intensity measure of moderate earthquake.

\section{Conclusions}

The probabilistic PBSD framework has been highlighted recently. In order to promote the familiarity and application of probabilistic PBSD method, the SSLEFCPM was proposed. Some conclusions could be obtained as follows.

The simplified seismic loss estimation framework is more easily to be understood and applied than the probabilistic PEER framework, which is more available to align the current assessment methods in design standards or design guidelines. The simplified framework could be a useful method to engineers in cost-benefit analysis.

The regulation of strong column and weak beam could be achieved in code-conforming RC frame, whereas the structure failure probability caused by column failure may be remarkable under rare earthquake. Furthermore, the structure may have to be demolished due to excessive expected seismic loss once the $P G A$ exceeds moderate earthquake.

\section{Acknowledgments}

The research described in this paper was financially supported by China Postdoctoral Science Foundation (2019M662917, 2019M662918, 2019M652899), the Science and technology planning project of Guangzhou Municipal Construction Group Co., Ltd(Granted No [2019]-KJ023), Natural Science Foundation of China (Granted No 51678171, 51908225), Postdoctoral International Training Program of Guangzhou and Peal River S\&T Nova Program of Guangzhou (Granted No 201806010095).

\section{References}

1. C.M. Ramirez, A.B. Liel, J. Mitrani-Reiser, et al: Earthquake Engng Struct Dyn 41, 7 (2012)

2. C.A. Cornell, H. Krawinkler: PEER Center News 3 (2000)

3. C.B. Haselton, C.A. Goulet, J. Mitrani-Reiser, et al: PEER Report, UC Berkeley (2008)

4. FEMA P58. Federal Emergency Management Agency, Washington (2012)

5. D. Cardone, G. Perrone: J EARTHQ ENG, 21 (2017)

6. D. Cardone, T.J. Sullivan, G. Gesualdi, et al: Earthquake Engng Struct Dyn, 46 (2017)

7. S.F. Qiao: Research on seismic fragility and bracing configuration of RC frame structure using component- performance -based methodology. $\mathrm{PhD}$ Thesis, South China University of Technology, Guangzhou (2018)

8. ASCE/SEI 41-13: Seismic evaluation and retrofit rehabilitation of existing building. American Society of Civil Engineers, USA (2013) 
9. X.X. Zhou, X.L. Han, J. Ji, et al: The Open Civil Engineering Journal, 10 (2016)

10. GBT 18208.4-2011: Earthquake field work- part 4: direct earthquake loss evaluation. Standards press of China, Beijing (2011)
11. GB 50011: Code for seismic design of buildings, Architecture Industry Press, Beijing (2016)

12. S.F. Qiao, X.L. Han, K.M. Zhou, et al: Steel Compos Struct, 23 (2017) 